\title{
FVC and FEV Reference Values for Beninese Individuals Aged 17 - 20 Years
}

\author{
Folly Messan ${ }^{*}$, Mohamed M. Lawani ${ }^{2}$, Daouda Mama ${ }^{3}$ \\ ${ }^{1}$ Laboratory of Respiratory, Hormonal and Gerontological Explorations of the Sportman, National Institute of Youth, Physical \\ Education and Sport (INJEPS), University of Abomey-Calavi, Cotonou, Republic of Benin \\ ${ }^{2}$ Laboratory of Biomechanics and Performance (LABIOP), National Institute of Youth, Physical Education and Sport (INJEPS), \\ University of Abomey-Calavi, Cotonou, Republic of Benin \\ ${ }^{3}$ Laboratory of Applied Hydrology, Faculty of Sciences and Technics, University of Abomey-Calavi, Cotonou, Republic of Benin \\ Email: *messfly@yahoo.fr
}

How to cite this paper: Messan, F., Lawani, M.M. and Mama, D. (2019) FVC and FEV Reference Values for Beninese Individuals Aged 17 - 20 Years. Open Journal of Respiratory Diseases, 9, 48-59. https://doi.org/10.4236/ojrd.2019.92005

Received: February 22, 2019

Accepted: May 14, 2019

Published: May 17, 2019

Copyright $\odot 2019$ by author(s) and Scientific Research Publishing Inc. This work is licensed under the Creative Commons Attribution International License (CC BY 4.0).

http://creativecommons.org/licenses/by/4.0/

\begin{abstract}
Background: 1) To determine forced vital capacity (FVC) and forced expiratory volume in one second (FEV) for Beninese individuals of both sexes aged 17 - 20 years; 2) Compare the observed values to those calculated based on the algorithms of the spirometer used. Materials and Methods: The FVC and FEV values were first measured using a Micro Quark spirometer and then calculated from equations for the European Respiratory Society-93 (ERS-93) in 148 subjects, including 46 girls. In each age group, the measured values for the height of the subjects were considered the only variables used to calculate the equations for FVC and FEV with their 95\% confidence intervals. The means of the FEV and FVC values were obtained by univariate analysis. Results: The calculated FEV and FVC values were significantly higher $(\mathrm{p}<0.05)$ than those observed by spirometry. Conclusion: The correction factors incorporated in spirometers imported from Europe no longer seem appropriate to measure the physical characteristics of African subjects. The differences between the two methods of assessment should be used as new ethnic correction factors.
\end{abstract}

\section{Keywords}

Reference Values, Correction Factors, Forced Vital Capacity, Forced Expiratory Volume in One Second, Benin

\section{Introduction}

Spirometry is a clinical examination to explore the respiratory function of healthy or ill subjects by the indirect evaluation of respiratory tract obstruction, bron- 
chial hyper-reactivity and restrictive syndrome. The spirometric results obtained at the end of the explorations allow the doctors to make a good diagnosis and identify latent respiratory pathologies [1] [2]. According to Bougrida et al. (2008), the evaluation of respiratory function is interpreted in relation to the expected values, called "normal values or reference values" [3]. Indeed, in the absence of reference values specific to the majority of African populations, African pneumologists use the reference values for Europeans in all categories [4] [5]. However, ventilatory variables are influenced by several factors, such as height, weight, race, sex, age and ethnicity [4] [5]. Thus, Dufetel et al. (1995) showed that the rate of growth of an African child was less rapid than that of a Caucasian child [6] [7] [8]. In addition, a recent study conducted in Benin in children aged 11 to 16 years [9] showed that the average values calculated for FVC and FEV were significantly $(\mathrm{p}<0.05)$ higher than those obtained with imported spirometers [10]. Under these conditions, the basis of interpretation of respiratory functional explorations no longer seems appropriate for young Africans aged 11 to 16 years. But what about those aged 17 to 20 ? Therefore, the present study examined different age categories of Beninese subjects to: 1) Determine the standard values of forced vital capacity (FVC) and forced expiratory volume during the first second (FEV) in individuals of both sexes aged 17 to 20 years old; 2) Compare the observed values of FVC and FEV with those produced by ERS-93 equations (ERS-93).

\section{Material and Methods}

The framework of the study: This study, conducted from February to May 2018 on 17- to 20-year-old students of "Fon", "Yoruba", "Goun" and other ethnic groups at BEHANZIN High School in Porto-Novo (Republic of Benin-West Africa), evaluates FVC and FEV reference values.

\subsection{Population and Sampling}

From two hundred and thirty-two (232) subjects recruited to take part in the study, only one hundred and forty-eight (148) subjects of both sexes, including one hundred and two (102) boys and forty-six (46) girls, were retained by the systematic sampling method after criteria of non-inclusion and exclusion (Table 1). The subjects are all students regularly enrolled at "BEHANZIN High School" in Porto-Novo. The participants were all informed of the purpose and process of the study and signed informed consent forms. Only 17- to 20-year-olds in age groups of 17, 18, 19 and 20 years were selected to participate in the study. High-level athletes, cardio respiratory-sensitive subjects, smokers and diabetic subjects identified from clinical examinations were excluded from the study. Similarly, subjects undergoing treatment that interfered with any aspect of lung function, obese individuals of class II and above, subjects with imperfectly performed respiratory manoeuvres and those who do not hold a valid identity card were excluded from this study (Table 1). All the subjects gave their informed 
Table 1. After criteria of non-inclusion and exclusion $(\mathrm{n}=148)$.

\begin{tabular}{cc}
\hline Brief description & $\begin{array}{c}\text { Number of "not included" and "excluded" } \\
\text { subjects in the study }\end{array}$ \\
\hline Imperfect ventilatory maneuvers & 09 \\
Respiratory history & 13 \\
Without identity or "Born to" subjects & 27 \\
Missing subjects & 34 \\
Body Mass Index $>35 \mathrm{~kg} \cdot \mathrm{m}^{-2}$ & 01 \\
& $84(\mathrm{n}=148=232-84)$ \\
\hline
\end{tabular}

written consents to take part in this study which was approved by the Scientific Committee of the Physical Activities and Sports Sciences and Techniques named CSS /STAPS, of the University of Abomey-Calavi, sitting as Ethics committee.

\subsection{Materials and Procedures}

\subsubsection{Materials}

The body mass was measured with a QE-2008C electronic scale; the size of the subjects was measured from zero to two metres using a measuring wall. The subjects stood barefoot in an anatomical reference position. The respiratory functional exploration was performed using disposable accessories and a Micro Quark $^{\oplus}$ spirometer (Cosmed SARL, Rome Italy) to avoid cross-contamination. The spirometer displayed the flow-volume curve on a monitor in real time during the exploration. The flow rate varied from 0.03 to $20 \mathrm{~L} / \mathrm{s}$, and the maximum volume was limited to $10 \mathrm{~L}$, with a precision of plus or minus $3 \%$, in accordance with the recommendations of the ERS [10] [11] and the American Thoracic Society (ATS) [12].

\subsubsection{Procedures}

A questionnaire inspired by the ATS [13] facilitated the collection of the clinical data for the subjects. The questions are essentially closed answers and most often dichotomous. In accordance with ATS/ERS recommendations [14], when measuring height, the head must be positioned in the Frankfurt horizontal plane [15]. The date of birth was noted under presentation of the birth certificate or national identity card. In addition to a valid piece of identification, additional questions were asked to certain subjects when the physical appearance was not consistent with their age. The body mass index [BMI = body mass divided by the square of height $\left(\mathrm{kg} \cdot \mathrm{m}^{-2}\right)$ ] was calculated for each age category. The ventilatory variables (FVC and FEV) of the flow/volume curve were measured using a Micro Quark spirometer (Cosmed SARL, Rome Italy). Every morning, the spirometer was calibrated using a calibration syringe (Cosmed SARL, Rome Italy) with a capacity of $3 \mathrm{~L}$ of atmospheric air. The Micro Quark met the criteria of the ATS/ERS with the consideration of African origin. Indeed, the selection of the "African origin" option of the spirometer refers to the equations of African American subjects (ITS Black) [16]. Mouthpieces and antibacterial filters for single 
use (Cosmed SARL, Rome Italy) were used to avoid the risk of cross-contamination. During the respiratory functional exploration, the subjects in standing position, with a pinched nose, and a turbine between the two hands, breathe naturally and calmly by the mouthpiece connected to the device of the spirometer. The subject is then instructed to inflate their lungs as much as possible and then empty the air as quickly as possible in a continuous and complete manner lasting not more than six seconds. At the end of the test, the best-sum flow-volume curve (FVC + FEV1) was retained according to the acceptability criteria recommended by the ERS/ATS [17].

\subsection{Determination of Standard FVC and FEV Values According to Our Study and ERS-93 Standards}

The height, FVC, and FEV values for subjects in each age and sex category were subjected to univariate analysis to determine their standard means and their $95 \%$ confidence intervals (results of our study). The respective mean values of the size and age variables will be introduced into the ERS-93 equations according to age and sex categories to determine the FVC and FEV reference values [10]. The differences between the standard values of our study and those of the ERS-93 standards (Table 2) will be determined by the calculation of the percentages of variations [10].

\subsection{Statistical Analysis}

The statistical analysis consisted of the following:

1) Recording and processing data using Stat view software (Version 5) from Abacus Concepts Inc. (Berkeley, CA, USA); 2) Checking normality and homogeneity of variance by the Kolmogorov-Smirnov test and the F-test; 3) Calculatingmeans and standard deviations (SD) and comparing by Student's t-test for un

Table 2. Equations of the ERS-93 incorporated in spirometers [10].

\begin{tabular}{ccc}
\hline PARAMETERS & EQUATIONS & SD \\
\hline FVC & A-For males subjects having less than 18 years old: & \\
FEV & $=7.9942-0.12509 \times \mathrm{H}+0.000605 \times \mathrm{H} 2 ;$ & 0.393 \\
& B-For female subjects having less than 18 years old: & 0.523 \\
FVC & $=0.169-0.01217 \times \mathrm{H}+0.000189 \times \mathrm{H} 2$ & 0.263 \\
FEV & $=0.0364 \times \mathrm{H}-3.0378 ;$ & 0.42 \\
& C-For male subjects having 18 years old and above: & \\
FVC & $=0.0576 \times \mathrm{H}-0.026 \times \mathrm{A}-4.34 ;$ & 0.61 \\
FEV & $=0.043 \times \mathrm{H}-0.029 \times \mathrm{A}-2.49 ;$ & 0.51 \\
& D-For females subjects having 18 years old and above: & \\
FVC & $=0.0443 \times \mathrm{H}-0.026 \times \mathrm{A}-2.89 ;$ & \\
FEV & $=0.0395 \times \mathrm{H}-0.025 \times \mathrm{A}-2.6 ;$ & 0.43
\end{tabular}

FVC: Forced Vital Capacity; FEV: Forced Expiratory Volume during the first second. FVC and FEV are in liter; Height $(\mathrm{H})$ in centimeter and Age $(\mathrm{A})$ in years. SD: Standard Deviation. 
paired series, mean values of anthropometric variables, and FVC and FEV between girls and boys; 4) Comparing by Student's t-series the paired series and average values of FVC observed with those obtained after the introduction of anthropometric variables in the ERS-93 reference equations; 5) Comparing by Student's paired t-test the mean values of the observed FEV to those obtained after the introduction of anthropometric variables in the ERS-93 reference equations; 6) Setting the likely threshold of significance at $\mathrm{p}<0.05$.

\section{Results}

After applying the non-inclusion and exclusion criteria (Table 1), of the 232 volunteers, only 148 "healthy" subjects (including 46 girls) were selected. Regardless of the age category considered for girls, the "Goun" ethnic group numerically dominated the other groups. On the other hand, for boys, this dominance of the "Goun" ethnic group was observed only in the 17, 18 and 20 year age groups.

\subsection{Standard Spirometric Reference Values}

The confidence intervals for the variables "height" and "age" with their standard values were calculated. Similarly, the confidence intervals for the FVC and FEV variables were established with their standard reference values. Each reference variable has a confidence interval of validity for each age and sex category. The standard size and age values were introduced into the ERS-93 equations to calculate FVC and FEV reference values [18].

\subsection{Comparisons of Standard Values with Those of ERS-93 Standards}

The FVC and FEV values recorded from the ERS-93 equations are significantly higher than those in our study, regardless of age and gender categories (Table 3) [18].

\subsection{Correction Factors}

The observed differences between the FEV and FVC values in our study and those recorded from the ERS-93 equations should be used as ethnic correction factors (Table 4).

\section{Discussions}

The major results of this study show that the ERS-93 standards [18] do not allow the accurate prediction of FVC and FEV in young Beninese individuals aged 17 to 20 years. Indeed, the values of FEV and FVC observed by respiratory explorations are significantly lower than those calculated on the basis of the same spirometer equations. The correction factors are taken by default. The determination of spirometric reference values is a concern for researchers worldwide. Studiesin several countries have already addressed this subject by using reference equa- 
Table 3. FVC and FEV values measured from our study compared to that calculated using the ERS-93 equations.

\begin{tabular}{|c|c|c|c|c|c|c|c|c|c|c|c|c|c|}
\hline $\begin{array}{l}\text { (A) } \\
\text { Age } \\
\text { Year }\end{array}$ & Sex & $\begin{array}{c}\text { (B) } \\
\text { IC_Age }\end{array}$ & $\begin{array}{c}\text { (C) } \\
\text { Age } \\
\text { our } \\
\text { Study }\end{array}$ & $\begin{array}{c}(\mathrm{D}) \\
\text { IC_- } \\
\text { Height }\end{array}$ & $\begin{array}{l}\text { (E) } \\
\text { Height } \\
(\mathrm{cm}) \\
\text { our } \\
\text { Study }\end{array}$ & $\begin{array}{c}(\mathrm{F}) \\
\text { IC_FVC } \\
(\mathrm{L}) \\
\text { our } \\
\text { Study }\end{array}$ & $\begin{array}{c}(\mathrm{G}) \\
\text { FVC } \\
(\mathrm{L}) \\
\text { our } \\
\text { standard }\end{array}$ & $\begin{array}{c}(\mathrm{H}) \\
\text { FVC } \\
(\mathrm{L}) \\
\text { Equation } \\
\text { ERS-93 }\end{array}$ & $\begin{array}{c}\text { (I) } \\
\text { Delta } \\
\%\end{array}$ & $\begin{array}{c}(\mathrm{J}) \\
\text { IC_FEV } \\
(\mathrm{L}) \\
\text { our } \\
\text { Study }\end{array}$ & $\begin{array}{c}\text { (K) } \\
\text { FEV } \\
(\mathrm{L}) \\
\text { our } \\
\text { Study }\end{array}$ & $\begin{array}{c}(\mathrm{L}) \\
\text { FEV } \\
(\mathrm{L}) \\
\text { Equation } \\
\text { ERS-93 }\end{array}$ & $\begin{array}{c}(\mathrm{M}) \\
\text { Delta } \\
\%\end{array}$ \\
\hline $17 \mathrm{yrs}$ & Boys & {$[17.5 ; 17.9]$} & 17.7 & {$[165.0 ; 168.5]$} & 166.8 & {$[3.1 ; 3.5]$} & 3.28 & $3.96^{*}$ & +20.78 & {$[2.5 ; 2.9]$} & 2.72 & $3.40^{*}$ & +24.98 \\
\hline $18 \mathrm{yrs}$ & Boys & {$[18.3 ; 18.6]$} & 18.4 & {$[169.4 ; 176.0]$} & 172.7 & {$[2.9 ; 3.6]$} & 3.21 & $5.13^{*}$ & +59.79 & {$[2.0 ; 2.8]$} & 2.43 & $4.40^{*}$ & +81.17 \\
\hline 19 yrs & Boys & {$[19.4 ; 19.7]$} & 19.4 & {$[168.1 ; 172.9]$} & 170.5 & {$[3.2 ; 3.6]$} & 3.37 & $4.98^{*}$ & +47.67 & {$[2.4 ; 2.9]$} & 2.67 & $4.28^{*}$ & +60.26 \\
\hline $20 \mathrm{yrs}$ & Boys & {$[20.4 ; 20.6]$} & 20.5 & {$[168.3 ; 174.1]$} & 171.2 & {$[3.2 ; 3.6]$} & 3.43 & $4.99^{*}$ & +45.43 & {$[2.6 ; 2.9]$} & 2.77 & $4.28^{*}$ & +54.41 \\
\hline $17 \mathrm{yrs}$ & Girls & {$[17.4 ; 17.9]$} & 17.6 & [157.6; 166.1] & 161.9 & {$[2.0 ; 3.1]$} & 2.57 & $3.15^{*}$ & +22.67 & {$[1.4 ; 2.6]$} & 2.02 & $2.86^{*}$ & +41.35 \\
\hline 18 yrs & Girls & {$[18.1 ; 18.2]$} & 18.2 & {$[158.2 ; 166.7]$} & 162.4 & {$[1.9 ; 2.8]$} & 2.37 & $3.83^{*}$ & +61.65 & {$[1.6 ; 2.5]$} & 2.06 & $3.36^{*}$ & +63.10 \\
\hline 19 yrs & Girls & {$[19.3 ; 19.6]$} & 19.4 & {$[154.0 ; 164.3]$} & 159.2 & {$[2.0 ; 2.8]$} & 2.44 & $3.66^{*}$ & +49.92 & {$[2.4 ; 2.9]$} & 1.92 & $3.20^{*}$ & +66.84 \\
\hline $20 \mathrm{yrs}$ & Girls & {$[20.4 ; 20.6]$} & 20.5 & {$[156.1 ; 165.0]$} & 160.5 & {$[1.9 ; 2.8]$} & 2.37 & $3.69^{*}$ & +55.58 & {$[1.7 ; 2.4]$} & 1.97 & $3.23^{*}$ & +63.82 \\
\hline
\end{tabular}

(A): different categories of age, year, and sex; (B): confidence intervals (CI) of age; (C): reference values of age compatible with IC; (D): IC of height; (E): reference values of height compatible with IC; (F): confidence intervals (CI) of FVC; (G) standard values of FVC according to IC; (H): FVC values obtained after introducing of the referential height in ERS/93 equation; (I: Delta \% $=\left(\mathrm{F}^{*} 100 / \mathrm{E}\right)-100$; (J): CI of FEV1; (K): standard values of FEV1 according to IC; (L): FEV1 values obtained after introducing of the referential height in ERS-93 equation; (M Delta $\%=\left(\mathrm{J}^{\star} 100 / \mathrm{I}\right)-100$; ${ }^{\star}$ ERS- 93 values significantly different $(P<0.05)$ from standard values in our study.

Table 4. Correction ethnic factors suggested by our study in Beninese children after using the micro Quark Spirometer (Cosmed, Italy) with "African origin" option.

\begin{tabular}{llcccc}
\hline $\begin{array}{c}\text { (A) } \\
\text { Age }\end{array}$ & Sex & $\begin{array}{c}(\mathrm{B}) \\
\text { IC_age } \\
\text { Year }\end{array}$ & $\begin{array}{c}(\mathrm{C}) \\
\text { IC_hear) } \\
(\mathrm{cm})\end{array}$ & $\begin{array}{c}\text { (D) } \\
\text { Correction ethnic of } \\
\text { FVC }(\%)\end{array}$ & $\begin{array}{c}\text { (E) } \\
\text { Correction ethnic of } \\
\text { FEV (\%) }\end{array}$ \\
\hline $17 \mathrm{yrs}$ & Boys & {$[17.5 ; 17.9]$} & {$[165.0 ; 168.5]$} & -20.78 & -24.98 \\
$18 \mathrm{yrs}$ & Boys & {$[18.3 ; 18.6]$} & {$[169.4 ; 176.0]$} & -59.79 & -81.17 \\
$19 \mathrm{yrs}$ & Boys & {$[19.4 ; 19.7]$} & {$[168.1 ; 172.9]$} & -47.67 & -60.26 \\
$20 \mathrm{yrs}$ & Boys & {$[20.4 ; 20.6]$} & {$[168.3 ; 174.1]$} & -45.43 & -54.41 \\
$17 \mathrm{yrs}$ & Girls & {$[17.4 ; 17.9]$} & {$[157.6 ; 166.1]$} & -22.67 & -41.35 \\
$18 \mathrm{yrs}$ & Girls & {$[18.1 ; 18.2]$} & {$[158.2 ; 166.7]$} & -61.65 & -63.10 \\
$19 \mathrm{yrs}$ & Girls & {$[19.3 ; 19.6]$} & {$[154.0 ; 164.3]$} & -49.92 & -66.84 \\
$20 \mathrm{yrs}$ & Girls & {$[20.4 ; 20.6]$} & {$[156.1 ; 165.0]$} & -55.58 & -63.82 \\
\hline
\end{tabular}

(A): different categories of age, year, and sex, (B): confidence intervals (CI) of age, (C): confidence intervals (CI) of height, (D) and (E): correction ethnic values of FVC and FEV observed respectively, with the micro Quark Spirometer.

tions, taking into account healthy children and adults based on their age, height, body mass, sex, and sometimes, their ethnic origins. The equations of the European Coal and Steel Community (ECSC) [18] and the equations of the Third National Health and Nutrition Examination Survey (NHANES III) were the most used worldwide [17]. These two main predictive equations and those observed in the literature are multiple regressions that simultaneously integrate several anthropometric variables. It is obvious that when the final value of an equation is determined from several measured variables, the measurement error is the sum of the errors for each variable. The sub-Saharan African countries, particularly Benin, do not yet have authentic tools of reference in spirometry for 
all age categories. Nevertheless, Messan et al. helped to fill this gap by establishing the first FVC and FEV baseline values for Beninese individuals aged 11 to 16 years [9]. The present study, as a continuation of the previous study, aims to develop standard FVC and FEV values with $95 \%$ confidence intervals for Beninese people of each age group from 17 to 20 years.

Moreover, possible variability in the results of different studies of spirometric reference values may be due to the nature of the studies. Indeed, Ware et al. (1990) observed cohort and period effects in longitudinal studies [19], while Guénard and Rouatbi (2004) highlighted the effects of selection specific to cross-sectional studies [20]. As a general rule, reference equations are established on cross-sectional samples obtained at the same time and in subjects of all ages. The variability of lung function over time is often minimized because of the linear ages of the subjects in the study. To eliminate any significant difference between the reference equations, the number of study samples should be approximately 100 subjects [21], and from this point of view, our 148-subject sample size responds well to this requirement. The criteria for non-inclusion were respected (Table 2). Although the criteria for defining "healthy" subjects have been the subject of recommendations published by the ATS and the ERS [4], the precise definition remains difficult to establish. However, to be considered as such, the subject must be a non-smoker and free from any pathology or respiratory condition [22]. Therefore, smokers and subjects with respiratory diseases were ruled out. The realization of spirometry requires the cooperation and effort of the subject under examination. As recommended by the ATS/ERS [23], subjects who are unable to properly perform the required breathing manoeuvres after a few trials were not included in the study. The population studied mainly comprised the "Goun" ethnic group. This dominance fits well and is observed in the age categories of 17, 18 and 20 years for boys. In total, the "Goun", "Yoruba", "Fon" and "Other" ethnic groups represent 47.29\%, 23.64\%, 16.89\% and 12.16\%, respectively, of the sample studied. The sample studied can be representative of the local population since $66 \%$ of the inhabitants of the city of Porto-Novo mainly consist of the "Goun" and "Fon" ethnic groups.

\section{Comparisons of Our Standard Values with Those of ERS-93}

For both girls and boys in all age categories considered, the mean FVC and FEV values observed on the basis of the ERS-93 [10] standards significantly exceeded $(\mathrm{p}<0.05)$ the standard values in our study (Table 3$)$. In all, the FVC and FEV variables observed in young Beninese individuals cannot be predicted by the ERS-93 standards for the age categories considered (17 to 20 years old), regardless of the gender, and these results are consistent with those of Messan et al. (2013) [9]. The partial explanations of these results come from a study by Jordan [24], which revealed that Caucasians constitute a genetically superior compact group that separates itself distinctly from African populations. Additionally, Caucasians have a genetic heritage that is very different from that of black Africans. From this point of view, these results indicate explanatory paths that could 
justify the differences in FVC and FEV values observed for both girls and boys in all age groups combined with European ERS-93 standards [10]. Indeed, the calculated standards significantly overestimate the FVC and FEV values observed by spirometry in young Beninese individuals. Similar results have been observed by Aggarwal et al. (2005) on 6814 subjects declared as having normal spirometry according to Indian references [25] showing that 53\%, 40\%, $14 \%$ and $10 \%$ of these subjects are identified as having abnormal spirometry according to the references of NHANES III [17], Crapo et al. (1981) [26], Knudson et al. (1983) [27] and European standards respectively [18]. Similarly, Olanrewaju (1991) showed that Nigerian school children aged 5 to 20 years have average FVC, FEV and DEP values significantly lower than their Caucasian counterparts [28] [29]. These results revealed average values for FVC and FEV calculated on the basis of the ERS-93 [10] standards, which significantly exceed $(p<0.05)$ the Beninese standard spirometric values. Hence, some authors emphasize the importance of ethnic impact when interpreting lung function tests in children [9] [28]. As a result, the interpretation of static volumes in black children is limited due to inappropriate reference equations. The reference equations can therefore only be applied to populations if they have similar morphological, socio-economic and ethnic characteristics. To minimize these biases, the ATS/ERS jointly recommended the application of ethnic correction factors to groups of subjects with no specific equation [14]. However, since 1983, Quanjer et al. had emphasized the inadequacy of a fixed correction or adjustment factors for Africans and Asians [18]. In addition, the research of Hankinson et al. (1999) confirmed the doubt related to the validity of these correction factors [30]. Indeed, in the context of the present study, the "African" origin was taken into account by the software of the Micro Quark spirometer (Cosmed, Italy) to correct the difference in morphotypes between black and Caucasian subjects. If so, then the measurement of ventilatory variables using this spirometer should not be significantly different in two black and Caucasian subjects of similar ages and sizes. Despite these corrective measures, the "corrected" European standards continue to significantly overestimate the predictive ventilatory variables in Beninese subjects. Similarly, Dufetel et al. (1990) showed in Africa that the total lung capacity among Togolese (in West Africa) men aged 25 to 55 years was lower by an average of $25 \%$, and the other lung volumes were also $22 \%$ lower than those men of the same age and size [31] [32]. In this context, the authors concluded that it would be wrong to use a proportionality factor to define the reference spirometric values for black children based on the standards defined for Caucasian subjects [31] [32]. The question then arises to know why, despite the ethnic corrections integrated into spirometers imported from Europe, the ventilatory variables measured in black African subjects are higher than those of their Caucasian counterparts of the same age, sex and height? The answer to this question is at several levels. Indeed, Dufetel et al. (1990) justified this difference by the fact that black children have smaller chest cages and longer limbs than Caucasian children, confirming that the rate of growth of physical characteristics is not the same from one ethnic 
group to another, given the different socio-economic and environmental conditions [31] [32]. In Brazil, for example, this reality is taken into account, especially as there are spirometric reference values applicable to adult white Brazilians different from those of other ethnic groups [33]. In addition, Pellegrino et al. (2005) justified these differences by the variability of criteria related to study group characteristics, such as age, height, and sex. Among the populations studied, the equations are significantly different according to sex [14]. Indeed, for each sex, there are age and size effects in young subjects related to maturation. These effects are often masked by groups of subjects of different ages. To overcome the difficulties and bias in the context of this study, we opted for each age category ranging from 17 to 20 years. At another level, Stanojevic et al. (2007) explained this dissimilarity in the values incorporated into calculation software that can vary significantly from one manufacturer to another or between research laboratories [34] [35]. Finally, the question of precise age has a great influence on the variability of referential spirometric data. Indeed, in the context of the studies that resulted in predictive equations, the chronological ages of the subjects often taken into account do not at all reflect the reality of the ages. As proof, a subject will have the same chronological age according to whether the analysis is conducted in January or December of the same year. From February to November, for 10 months, the height and lung size of the subject did not change. In these circumstances, is Marks (2012) right when he asks whether or not the spirometric reference equations are truly appropriate for diagnosing lung diseases [36]? It is precisely this bias that Quanjer et al. (2012) would like to avoid by developing in "the framework of the Global Lung Function Initiative", a software tool that makes it possible to accurately determine the age of the subject on the basis of his date of birth and that of the day of the experiment [37]. Indeed, these ages are obtained with decimals. This precise age problem is more crucial in Africa, especially since thousands of children do not have a birth certificate. Moreover, even if they do, the chronological age is usually inconsistent with the biological age because of age exemptions made either by the children or their parents. Under these conditions, the present study was based not only on the chronological ages obtained from the identity documents but also on the biological age through questions of curiosity to which the subjects answered. In total, we noticed that the anthropological and environmental realities of African countries differ from those of Northern countries. As a result, the different reference values obtained using the reference equations incorporated in the spirometers constructed in European countries significantly overestimate the actual values observed by spirometry. Indeed, the ethnic correction factors considered in the 1980s are taken by default.

\section{Conclusion}

In summary, the spirometric reference values are very useful in interpreting the results of the examinations of respiratory function. The major results of this study plied to African subjects through ethnic correction factors incorporated in the 
spirometers. However, imported spirometers produce FVC and FEV parameters that do not match the physical characteristics of young Beninese individuals. Discrepancies between the two assessment modalities should be used as new ethnic correction factors. The new spirometric reference values could be used in countries of the sub-region that do not yet have them. Clearly, these standard values would help paediatricians and clinicians detect lung diseases and early problems of growth and malnutrition specifically in the African context.

\section{Conflicts of Interest}

The authors declare no conflicts of interest regarding the publication of this paper.

\section{References}

[1] Quanjer, P.H., Tammeling, G.J., Cotes, J.E., Pedersen, O.F., Peslin, R. and Yernault, J.-C. (1993) Lung Volumes and Forced Ventilatory Flows. European Respiratory Journal, 6, 5-40. http://www.ncbi.nlm.nih.gov/pubmed/24576915 https://doi.org/10.1183/09041950.005s1693

[2] Ahmed, R., Robinson, R. and Mortimer, K. (2017) The Epidemiology of Noncommunicable Respiratory Disease in Sub-Saharan Africa, the Middle East, and North Africa. Malawi Medical Journal, 29, 203-211. http://www.ncbi.nlm.nih.gov/pubmed/28955434 https://doi.org/10.4314/mmj.v29i2.24

[3] Bougrida, M., Ben, S.H., KheireddinneBourahli, M. and Bougmiza, I.M.H. (2008) Équations de référence spirométriques des Algériens âgés de 19 à 73 ans. Revue des Maladies Respiratoires, 25, 577-590. https://doi.org/10.1016/S0761-8425(08)71615-2

[4] Seconde Edition Française des recommandations européennes pour les explorations fonctionnelles respiratoires. (2001) La Revue des Maladies Respiratoires, 18, 13-52.

[5] Arigliani, M., Canciani, M.C., Mottini, G., Altomare, M., Magnolato, A., Loa Clemente, S.V., et al. (2017) Evaluation of the Global Lung Initiative 2012 Reference Values for Spirometry in African Children. American Journal of Respiratory and Critical Care Medicine, 195, 229-236. https://doi.org/10.1164/rccm.201604-06930C http://www.atsjournals.org/doi/10.1164/rccm.201604-0693OC

[6] Dufetel, P., Wazni, A., Gaultier, C.I., Derossi, G., Cisse, F., et al. (1995) Croissance et fonction ventilatoire chez l'enfant et l'adolescent noirs. Revue des Maladies Respiratoires, 12, 135-143.

[7] Nwosu, N.I., Chukwuka, C.J., Onyedum, C.C., Odilinye, H.C., Nlewedim, P.I. and Ayuk, A.C. (2016) Current Pattern of Spirometry Utilisation in a Sub-Saharan African Country. African Journal of Respiratory Medicine, 12, 15-20.

[8] Zar, H.J., Vanker, A., Gray, D. and Zampoli, M. (2017) The African Pediatric Fellowship Training Program in Pediatric Pulmonology: A Model for Growing African Capacity in Child Lung Health. Annals of the American Thoracic Society, 14, 500-504. http://www.atsjournals.org/doi/10.1513/AnnalsATS.201612-953PS https://doi.org/10.1513/AnnalsATS.201612-953PS

[9] Messan, F., Dansou, P., Marqueste, T., Decherchi, P., Tossou, R., Amoussou, T., et al. (2013) First Report of FVC and FEV1 Reference Values for Beninese Children Aged 11-16 Years. ISRN Pulmonology, 2013, Article ID: 284386. https://doi.org/10.1155/2013/284386 
[10] Quanjer, P.H., Stocks, J., Polgar, G., Wise, M., Karlberg, J., et al. (1989) Compilation of Reference Values for Lung Function Measurements in Children. European Respiratory Journal, 4, 184S-216S.

[11] ERS (1993) Standardized Lung Function Testing. European Respiratory Journal, 6, 53-83.

[12] ATS (1995) Standardization of Spirometry. American Journal of Respiratory and Critical Care Medicine, 152, 1107-1136. https://doi.org/10.1164/ajrccm.152.3.7663792

[13] Ferris, B.G. (1978) Epidemiology Standardization Project II: Recommended Respiratory Disease Questionnaires for Use with Adults and Children in Epidemiological Research. The American Review of Respiratory Disease, 118, 7-57.

[14] Pellegrino, R., Viegi, G., Brusasco, V., et al. (2005) Stratégies d'interprétation des explorations fonctionnelles respiratoires. European Respiratory Journal, 26, 948-968.

[15] Lohan, T.G., Roche, A.F., et al. (1998) Anthropometric Standardization Reference Manual. Human Kinetics, Champaign, 1-55.

[16] Morris, A., Kanner, R.E., Crapo, R., et al. (1984) Clinical Pulmonary Function Testing. A Manual of Uniform Laboratory Procedures. Intermountain Thoracic Society, Salt Lake City, 1-24.

[17] Wanger, J., Clausen, J.L., Coates, A., et al. (2005) Standardization of the Measurement of Lung Volumes. European Respiratory Journal, 26, 511-522. https://doi.org/10.1183/09031936.05.00035005

[18] Quanjer, P.H., Dalhusen, A., et al. (1983) Summary Equations of References Values. Bulletin Europeen de Physiopathologie Respiratoire, 19, 45-51.

[19] Ware, J.H., Dockery, D.W., Louis, T.A., Xu, X.P., Ferris, B.G., et al. (1990) Longitudinal and Cross-Sectional Estimates of Pulmonary Function Decline in Never-Smoking Adults. American Journal of Epidemiology, 132, 685-700. https://doi.org/10.1093/oxfordjournals.aje.a115710

[20] Guénard, H. and Rouatbi, S. (2004) Aspects physiologiques du vieillissement respiratoire. Revue des Maladies Respiratoires, 21, 13-24.

https://doi.org/10.1016/S0761-8425(04)71558-2

[21] Jensen, R.L., Crapo, R.O., Flint, A.K., et al. (2002) Problems in Selecting Representative Reference Values and Interpretative Strategies. American Journal of Respiratory and Critical Care Medicine, 165, A200.

[22] Becklake, M., Crapo, R., Buist, S., Burrows, B., et al. (1991) Lung Function Testing: Selection of Reference Values and Interpretative Strategies. American Thoracic Society. The American Review of Respiratory Disease, 144, 1202-1218. https://doi.org/10.1164/ajrccm/144.5.1202

[23] Miller, M.R., Hankinson, J., Brusasco, V., et al. (2006) Série du groupe de travail ATS/ERS: Standardisation des explorations fonctionnelles respiratoires: Standardisation de la spirométrie. Revue des Maladies Respiratoires, 23, 17S23-17S45.

[24] Jordan, B. (2010) DNA, Genetic Superiority and Social "'Race”: The Contribution of SNPs. Medical Sciences, 26, 215-218. https://doi.org/10.1051/medsci/2010262215

[25] Aggarwal, A.N., Gupta, D., Behera, D., et al. (2005) Applicability of Commonly Used Caucasian Prediction Equations for Spirometry Interpretation in India. Indian Journal of Medical Research, 122, 153-164.

[26] Crapo, R.O., Morris, A.H., et al. (1981) Reference Spirometric Values Using 
Techniques and Equipment That Meet ATS Recommendations. The American Review of Respiratory Disease, 123, 659-664.

[27] Knudson, R.J., Lebowitz, M.D., Holberg, C.J., et al. (1983) Changes in the Normal Maximal Expiratory Flow-Volume Curve with Growth and Aging. The American Review of Respiratory Disease, 127, 725-734.

[28] Olanrewaju, D.M. (1991) Spirometric Standards for Healthy Nigerian Children and Adolescents. East African Medical Journal, 68, 812-819.

[29] Obaseki, D., Adeniyi, B., Kolawole, T., Onyedum, C. and Erhabor, G. (2015) Gaps in Capacity for Respiratory Care in Developing Countries. Nigeria as a Case Study. Annals of the American Thoracic Society, 12, 591-598. https://doi.org/10.1513/AnnalsATS.201410-443AR

[30] Hakinson, J.L., Odencrantz, J.R., et al. (1991) Spirometric Reference Values from a Sample of General U.S. Population. American Journal of Respiratory and Critical Care Medicine, 159, 179-187. https://doi.org/10.1164/ajrccm.159.1.9712108

[31] Dufetel, P., Sambiani, K., Togbey, K., et al. (1990) Particularités des volumes pulmonaires et débits expiratoires observés chez l'adulte noir. Revue des Maladies Respiratoires, 7, 215-222.

[32] Kibirige, D., Kampiire, L., Atuhe, D., Mwebaze, R., Katagira, W., Muttamba, W., et al. (2017) Access to Affordable Medicines and Diagnostic Tests for Asthma and COPD in Sub Saharan Africa: The Ugandan Perspective. BMC Pulmonary Medicine, 17, 179. https://doi.org/10.1186/s12890-017-0527-y

[33] Carlos Alberto de Castro, P., Taeko, S., et al. (2007) New Reference Values for Forced Spirometry in White Adults in Brazil. The Jornal Brasileiro de Pneumologia, 33, 397-406. https://doi.org/10.1590/S1806-37132007000400008

[34] Stanojevic, S., Wade, A., Cole, T.J., et al. (2007) Population-Specific Reference Equations? European Respiratory Journal, 29, 215.

https://doi.org/10.1183/09031936.00119606

[35] Paton, J., Beardsomore, C., Laverty, A., et al. (2012) Discrepanices between, Pediatric Laboratories in Pulmonary Function Results from Healthy Children. Pediatric Pulmonology, 47, 588-596. https://doi.org/10.1002/ppul.21592

[36] Marks, G.B. (2012) Are Reference Equations for Spirometry an Appropriate Criterion for Diagnosing Disease and Predicting Prognosis? Thorax, 67, 85-87. https://doi.org/10.1136/thoraxjnl-2011-200584

[37] Quanjer, P.H., Stanojevic, S., Cole, T.J., et al. (2012) ERS Global Lung Function Initiative. Multi-Ethnic Reference Values for Spirometry for the 3-95 yr Age Range: The Global Lung Function Equations. European Respiratory Journal, 40, 1324-1343. https://doi.org/10.1183/09031936.00080312 